Original Article

\title{
Medium- and long-chain triglyceride propofol reduces the activity of acetyl-coenzyme A carboxylase in hepatic lipid metabolism in HepG2 and Huh7 cells
}

\author{
Li-yuan Wang ${ }^{1}$, Jing Wu' ${ }^{2}$, Ya-fen Gao', Duo-mao Lin ${ }^{1}$, and Jun Ma'* \\ 'Center for Anesthesiology, Beijing Anzhen Hospital, Capital Medical University, Beijing 100029, ${ }^{2}$ North China University of Science and Technology, Tangshan, \\ Hebei 063300, P.R China
}

\section{ARTICLE INFO}

Received May 23, 2019

Revised August 23, 2019

Accepted September 2, 2019

*Correspondence

Jun Ma

E-mail: majun7689@163.com

\section{Key Words}

Hepatocytes

Liver

Metabolism

Propofol
ABSTRACT Medium- and long-chain triglyceride (MCT/LCT) propofol is widely used as an intravenous anesthetic, especially in the intensive care unit. The present study aimed to assess whether MCT/LCT propofol is safe in the hyperlipidemic population for long-term use. Free fatty acids (FFAs) were used to establish high-fat stimulation of HepG2 and Huh7 cells. Subsequently, these cells were treated with propofol at the concentration of 0,4 , or $8 \mu \mathrm{g} / \mathrm{ml}$ for 24 and $48 \mathrm{~h}$. The results indicated that the cell viability was notably decreased when the cells were stimulated with $2 \mathrm{mmol} / \mathrm{L}$ FFAs and treated with $12 \mu \mathrm{g} / \mathrm{ml} \mathrm{MCT/LCT} \mathrm{propofol.} \mathrm{Accordingly,} \mathrm{we} \mathrm{chose} 2 \mathrm{mmol} / \mathrm{L}$ FFAs along with 4 and $8 \mu \mathrm{g} / \mathrm{ml} \mathrm{MCT/LCT} \mathrm{propofol} \mathrm{for} \mathrm{the} \mathrm{subsequent} \mathrm{experiments.} \mathrm{Four}$ and $8 \mu \mathrm{g} / \mathrm{ml} \mathrm{MCT/LCT} \mathrm{propofol} \mathrm{inhibited} \mathrm{FFA-induced} \mathrm{lipid} \mathrm{accumulation} \mathrm{in} \mathrm{the} \mathrm{cells}$ and significantly reversed acetyl coenzyme A carboxylase (ACC) activity. In addition, MCT/LCT propofol not only significantly promoted the phosphorylation of AMPK and ACC, but also reversed the FFA-induced decreased phosphorylation of AMPK and ACC. In conclusion, MCT/LCT propofol reverses the negative effects caused by FFAs in HepG2 and Huh7 cells, indicating that MCT/LCT propofol might positively regulate lipid metabolism.

\section{INTRODUCTION}

Nonalcoholic fatty liver disease (NAFLD) is becoming a global epidemic, with a morbidity of up to $20 \%$, even reaching $75 \%-92 \%$ in obese individuals in the United States [1]. The early manifestation of NAFLD is altered lipid metabolism, resulting in hyperlipidemia. Obesity and other diseases are considered the "first hit" in NAFLD pathogenesis, and the "second hit" is deemed to be lipid peroxidation and oxidative stress caused by excessive hepatic triglyceride storage [2].

Medium- and long-chain triglyceride (MCT/LCT) propofol is a common drug used for clinical anesthesia and sedation. Compared with long-chain triglyceride (TG) propofol, propofol formulated in medium- and long-chain TGs is thought to cause less pain when injected and has a more rapid TG elimination, and thus, it is widely used clinically [3-5]. A single intravenous injection of MCT/LCT propofol is rapidly redistributed in vivo, followed by metabolism in the liver. However, extrahepatic factors, such as renal excretion and hemodilution, also affect the efficacy of propofol, and thus, blood propofol levels decrease quickly. MCT/LCT propofol has a phenolic hydroxyl group that is easily oxidized causing polymerization. This group blocks many pathways involved in pathophysiological changes of oxidative stress, such as free-radical-mediated lipid peroxidation, membrane structure and mobility changes [6,7]. Meanwhile, MCT/LCT propofol also improves the cell's ability to reduce antioxidant damage, hydroxyl radical levels and oxidative stress $[8,9]$. However, the effects of the use of propofol over a long period of time in (i) \$ This is an Open Access article distributed under the terms of the Creative Commons Attribution Non-Commercial License, which permits unrestricted non-commercial use, distribution, and reproduction in any medium, provided the original work is properly cited. Copyright @ Korean J Physiol Pharmacol, pISSN 1226-4512, elSSN 2093-3827
Author contributions: L.Y.W. and J.M. designed experiments; L.Y.W., J.W. and Y.F.G. carried out experiments; L.Y.W. and D.M.L. analyzed experimental results. L.Y.W. wrote the manuscript; J.M. approved the manuscript. 
clinical sedation are unclear. In addition, the minimum effective dose of propofol is unknown along with how to prevent possible adverse effects in patients with hyperlipidemia. Thus, a better understanding the cellular effects of MCT/LCT propofol in vitro would contribute to finding these answers.

The synthesis of fatty acids in the liver requires ATP citrate synthase, acetyl coenzyme A carboxylase (ACC) and fatty acid synthetase, and among these, the most easily regulated is ACC. ACC catalyzes the first reaction of fatty acid synthesis to produce fatty acid carbon chains, promoting the further synthesis of longchain fatty acids. Changes in the expression and activation of key molecules synthesized by ACC directly affect the uptake and synthesis of hepatic fatty acids. Excessive fatty acid oxidation, degradation and secretion leads to fatty acid degeneration in the liver [10]. One study showed that the ACC content in the adipose tissue and liver of obese patients was significantly higher than it those of their counterparts with a normal body weight [11]. ACC has two main isoforms, including ACC1 and ACC2. ACC1 is found in the cytoplasm of liver cells, where it catalyzes acetyl-CoA carboxylase to malonyl CoA and promotes fatty acid synthesis [12]. ACC2 is mainly expressed in the mitochondria. Animals lacking ACC2 are healthy and have good metabolic characteristics. In contrast, the lack of ACC1 leads to embryonic death. However, ACC1 +/mice show no abnormalities in the de novo synthesis hepatocyte fatty acids or the $\beta$-oxidation pathways [13].

The energy sensor AMP-activated protein kinase (AMPK) is a key player in the regulation of energy metabolism [14-17] through its repression of fatty acid and TG synthesis [18]. Importantly, AMPK regulates hepatic lipid metabolism via the phosphorylation of its well-recognized downstream target ACC [19-22].

Herein, we hypothesized that when HepG2 and Huh7 cells are treated with MCT/LCT propofol after stimulation with free fatty acids (FFAs), the cellular lipid metabolism is altered. Thus, in the present study, we examined the ACC/AMPK signaling pathway using this high-fat cell culture model to uncover the molecular mechanism regulating this phenomenon.

\section{METHODS}

\section{Cell culture}

HepG2 and Huh7 cells were cultured in Dulbecco's minimum essential medium (DMEM) containing 10\% fetal bovine serum (FBS), $100 \mathrm{U} / \mathrm{ml}$ penicillin and $100 \mu \mathrm{g} / \mathrm{ml}$ streptomycin in an incubator with $5 \% \mathrm{CO}_{2}$ at $37^{\circ} \mathrm{C}$. A total of $24 \mathrm{~h}$ later, the medium was refreshed. At a confluence of $80 \%$, the cells were passaged after digestion by trypsin (0.1\%). All the cells used in this study were in the logarithmic growth period. This study was approved by the ethical committee of Beijing Anzhen Hospital, Capital Medical University (201832X).

\section{Cell viability}

Cell viability was assessed using an MTT assay (SIGMA, St. Louis, MO, USA). The cells were seeded into 96 -well plates $(2,500$ cells/well) for $24 \mathrm{~h}$ at $37^{\circ} \mathrm{C}$ and were treated with FFAs and MCT/ LCT propofol at different concentrations. The DMEM containing buffer A was used as the control. After the treatment, the cells were washed with phosphate buffered saline (PBS) and were incubated with MTT and incubated at $37^{\circ} \mathrm{C}$ for $4 \mathrm{~h}$. Then, dimethyl sulfoxide was added to each well and was mixed completely. The absorbance was read at $490 \mathrm{~nm}$. The experiments were repeated at least three times.

\section{High-fat stimulation}

At total of $1 \times 10^{6}$ HepG2 and Huh7 cells (American Type Culture Collection, Manassas, VA, USA) were seeded into 6-well plates, and they were cultured in DMEM containing $10 \% \mathrm{FBS}$, $100 \mathrm{U} / \mathrm{ml}$ penicillin and $100 \mu \mathrm{g} / \mathrm{ml}$ streptomycin. A total of $24 \mathrm{~h}$ later, the cells were treated with $2 \mathrm{mmol} / \mathrm{L}$ FFA (SIGMA) for $24 \mathrm{~h}$.

\section{Propofol intervention}

MCT/LCT propofol was purchased from Fresenius-Kabi (Bad Homburg, Germany). The cells were seeded in $35 \mathrm{~mm}$ culture dishes at a density of $2 \times 10^{5}$ cells $/ \mathrm{mm}$. Seven groups were set, including the blank control group $(0 \mu \mathrm{g} / \mathrm{ml})$, MCT/LCT propofol group $1(4 \mu \mathrm{g} / \mathrm{ml}$ for $24 \mathrm{~h})$, MCT/LCT propofol group $2(4 \mu \mathrm{g} / \mathrm{ml}$ for $48 \mathrm{~h}$ ), MCT/LCT propofol group $3(4 \mu \mathrm{g} / \mathrm{ml}$ for $72 \mathrm{~h}$ ), MCT/ LCT propofol group $4(8 \mu \mathrm{g} / \mathrm{ml}$ for $24 \mathrm{~h})$, MCT/LCT propofol group $5(8 \mu \mathrm{g} / \mathrm{ml}$ for $48 \mathrm{~h})$, and MCT/LCT propofol group 6 (8 $\mu \mathrm{g} / \mathrm{ml}$ for $72 \mathrm{~h}$ ). The seven groups were incubated in a humidified environment at $37^{\circ} \mathrm{C}$ with $5 \% \mathrm{CO}_{2}$. The medium containing propofol in the propofol intervention groups was replaced every $24 \mathrm{~h}$. At each time point, the medium in propofol intervention groups 1 to 6 was replaced with fresh medium without propofol. The medium in the blank control group was replaced with medium without propofol every $24 \mathrm{~h}$. All the cells were cultured in an incubator for $72 \mathrm{~h}$. The incubation times and dosages were based on previous in vitro studies $[23,24]$.

\section{Oil red $O$ staining}

After the treatment described in above, the cells were washed with PBS and were fixed with 10\% formalin for $30 \mathrm{~min}$. Subsequently, the cells were stained with an Oil Red O working solution (SIGMA) for $30 \mathrm{~min}$ at room temperature. After extraction with $100 \%$ isopropanol, the Oil Red O content was quantified by evaluating the absorbance of each well with a spectrophotometer at $490 \mathrm{~nm}$. 


\section{TG content measurement}

The TG content in the cell lysates was measured using a commercial kit (Sigma-Aldrich, St Louis, MO, USA). The cell lysates (from $5 \times 10^{5} / 60 \mathrm{~mm}$ Petri dishes) were prepared on ice and were incubated with 2\% TritonX-100 (Amresco, Solon, OH, USA) according to the manufacturer's instructions. The protein concentrations were determined using a BCA Protein Assay Kit (SIGMA). The results are expressed as $\mathrm{mM} / \mathrm{g}$.

\section{Detection of ACC1 activity}

After the various treatments, the cells $\left(1 \times 10^{5} / \mathrm{ml}\right)$ were subjected to repeated freezing and thawing for lysis and for promoting the release of their intracellular components. Then, the samples were centrifuged for $20 \mathrm{~min}$ at 3,000 rpm, and the supernatants were carefully collected. In case of precipitation during preservation, the centrifugation was carried out again before using the samples. After the washing solution $(300 \mu \mathrm{l})$ was added into the wells, the samples were mixed gently for $30 \mathrm{sec}$, and the plates were blotted on absorbent paper, and this was repeated for a total of 5 times. Then, the cells were incubated with the ACC1 antibody (Bioscience, San Diego, CA, USA) and were washed again. After the chromogenic reaction, the absorbance was read at 450 $\mathrm{nm}$.

\section{Western blot}

The total proteins were extracted using lysis buffer. Equal amounts of the protein were separated using $10 \%$ sodium dodecyl sulfate-polyacrylamide gel electrophoresis and were transferred to polyvinylidene difluoride membranes. The membranes were blocked for $1 \mathrm{~h}$ at room temperature using 5\% nonfat milk and were incubated overnight at $4^{\circ} \mathrm{C}$ in the appropriate primary antibody, which included rabbit anti-p-ACC (abcam, 1:250), rabbit anti-ACC (abcam, 1:250), rabbit anti-p-AMPK (abcam, 1:250), rabbit anti-AMPK (abcam, 1:250) and rabbit anti-GAPDH (abcam, 1:250). Then, the membranes were washed 3 times for 10 min each with Tris-buffered saline containing Tween and were incubated with horseradish peroxidase-conjugated secondary antibodies for $1 \mathrm{~h}$ at room temperature. Following additional washes, the immunoreactive proteins on the membrane were visualized with enhanced chemiluminescence plus reagents (Millipore, Plano, TX, USA). The intensities of the immunoreactive proteins were measured via image J and were normalized to GAPDH. All the experiments were repeated at least 3 times.

\section{Statistical analysis}

The data are expressed as the mean \pm standard deviation and are illustrated using GraphPad 5 software (GraphPad Software, Inc., San Diego CA, USA). The SPSS 17.0.1 (SPSS Inc., Chicago, IL, USA) software was used for the statistical analysis. The data were assessed by ANOVA or a Student's t-test. $\mathrm{p}<0.05$ was con-
A
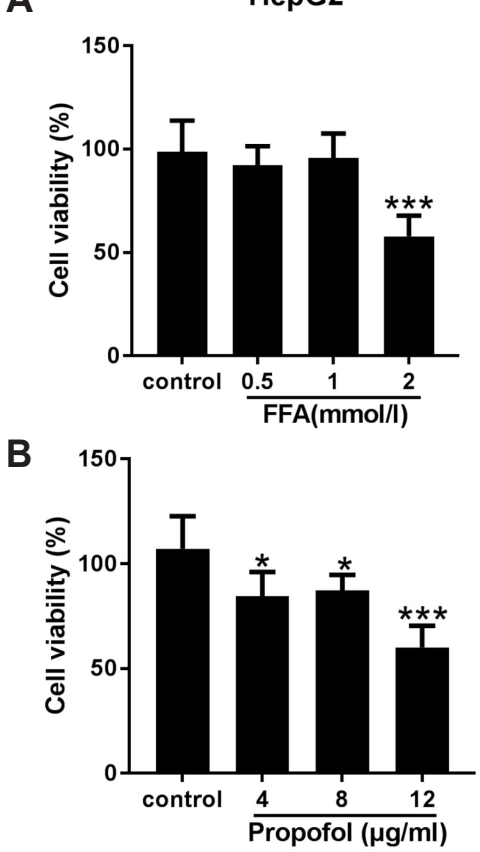

Huh7
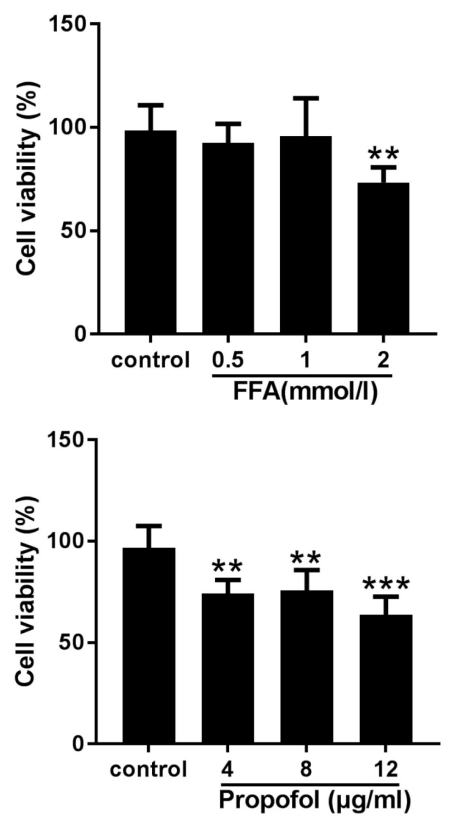

Fig. 1. Cytotoxicity of free fatty acid (FFA) and medium- and long-chain triglyceride (MCT/LCT) propofol on hepatocytes. (A) HepG2 and Huh7 cells were treated with different concentrations of FFA, MTT was used to evaluate the cell viability. (B) HepG2 and Huh7 cells were treated with different concentrations of MCT/LCT propofol, then evaluated the cell viability. ${ }^{*} p<0.05,{ }^{* *} p<0.01,{ }^{* * *} p<0.001$ vs. control group. 
sidered statistically significant.

\section{RESULTS}

\section{Cytotoxicity of FFA and MCT/LCT propofol on HepG2 and Huh7 cells}

The effects of the different concentrations of FFAs and MCT/ LCT propofol on cell viability were examined using an MTT assay. Cell viability was not affected by the use of FFAs up to 1 $\mathrm{mmol} / \mathrm{L}$ and $8 \mu \mathrm{g} / \mathrm{ml} \mathrm{MCT/LCT} \mathrm{propofol} \mathrm{in} \mathrm{human} \mathrm{HepG2} \mathrm{and}$ Huh7 cells (Fig. 1A, B). However, cell viability notably decreased when the FFA concentration was $2 \mathrm{mmol} / \mathrm{L}$ and when $12 \mu \mathrm{g} / \mathrm{ml}$ $\mathrm{MCT} / \mathrm{LCT}$ propofol was used. Thus, we used $1 \mathrm{mmol} / \mathrm{L}$ FFAs along with 4 and $8 \mu \mathrm{g} / \mathrm{ml} \mathrm{MCT/LCT} \mathrm{propofol} \mathrm{for} \mathrm{the} \mathrm{subsequent}$ experiments.

\section{MCT/LCT propofol inhibits FFA-induced lipid accumulation in HepG2 and Huh7 cells}

In order to evaluate the effect of MCT/LCT propofol on lipid accumulation, after the FFA and MCT/LCT propofol treatment, cell proliferation and TG content were assessed. We found that 1 mmol/L FFA significantly increased the TG content compared to that in the control group. In addition, the Oil Red O staining results suggested that the FFAs caused the hepatic lipids to accumulate. The MCT/LCT propofol treatment partially reversed the effects of the FFAs (Fig. 2A, B). These data suggested that MCT/ LCT propofol does not exacerbate the negative effects caused by
FFAs and actually may demonstrate some type of beneficial effect.

\section{MCT/LCT propofol inhibits ACC1 activity in HepG2 and Huh7 cells}

Next, we assessed ACC1 activity in the cells after the MCT/ LCT propofol treatment. The MCT/LCT propofol treatment decreased the ACC1 activity in the HepG2 and Huh7 cells after 24 and $48 \mathrm{~h}$ of treatment at both 4 and $8 \mu \mathrm{g} / \mathrm{ml}$ of MCT/LCT propofol (Fig. 3A, B). These data suggested that the MCT/LCT propofol treatment lowered lipid metabolism in the cells, which might lead to reduced fatty acid synthesis and fat accumulation in the cells.

\section{MCT/LCT propofol promotes the phosphorylation of ACC in HepG2 and Huh7 cells}

Next, the phosphorylation of ACC was assessed using a western blot analysis. The results revealed that the MCT/LCT propofol treatment promoted the phosphorylation of ACC (p-ACC Ser79) in the HepG2 and Huh7 cells after 24 and $48 \mathrm{~h}$ of treatment with both 4 and $8 \mu \mathrm{g} / \mathrm{ml}$ of MCT/LCT propofol (Fig. 4A, B). These data further support that fatty acid synthesis might be reduced by the MCT/LCT propofol treatment due the fact that it phosphorylates ACC in the cells.
A

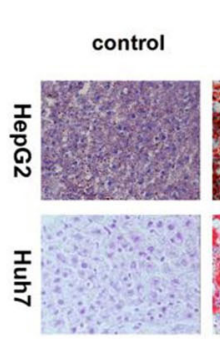

B

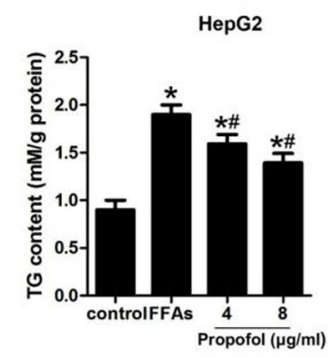

FFAs

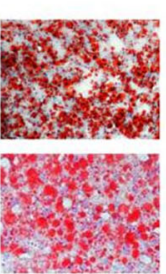

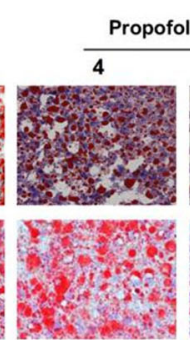
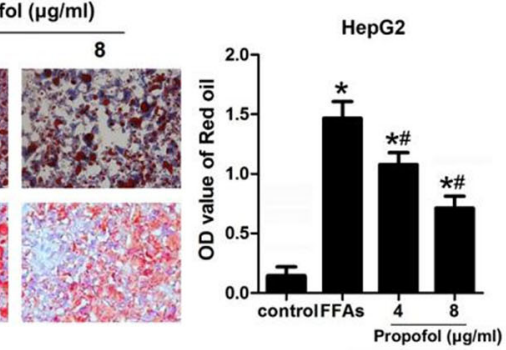

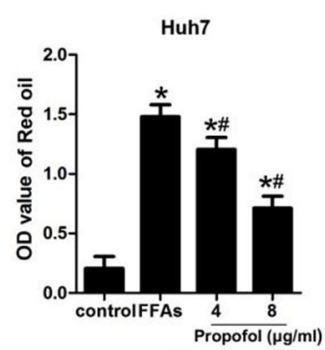

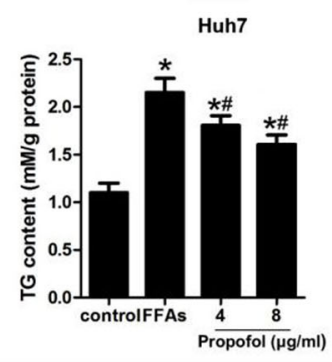

Fig. 2. Medium- and long-chain triglyceride (MCT/LCT) propofol inhibited free fatty acid (FFA)-induced lipid accumulation in HepG2 and Huh7 cells. (A) After FFA and $4 \mu \mathrm{g} / \mathrm{ml}$ or $8 \mu \mathrm{g} / \mathrm{ml} \mathrm{MCT/LCT} \mathrm{propofol} \mathrm{treatment,} \mathrm{Oil} \mathrm{Red} \mathrm{O} \mathrm{staining} \mathrm{was} \mathrm{used} \mathrm{to} \mathrm{detect} \mathrm{the} \mathrm{accumulation} \mathrm{of} \mathrm{hepatic}$ lipids. Relative intracellular lipid level was determined in HepG2 and Huh7 cells (Oil Red O staining, magnification, $\times 400$ ). (B) After $4 \mu \mathrm{g} / \mathrm{ml}$ or $8 \mu \mathrm{g} / \mathrm{ml}$ MCT/LCT propofol treatment, the TG content in different groups were detected. ${ }^{*} p<0.05$ vs. control group, ${ }^{*} p<0.05$ vs. FFA group. 
A

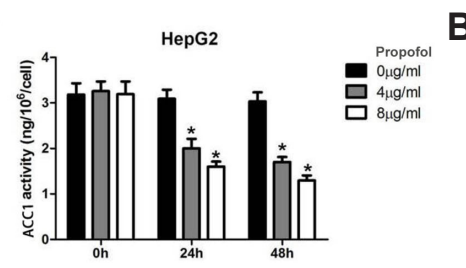

B

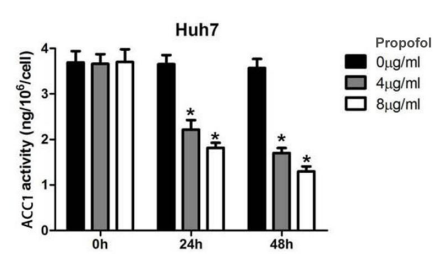

Fig. 3. Medium- and long-chain triglyceride propofol inhibited acetyl coenzyme A carboxylase (ACC)1 activity in HepG2 and Huh7 cells. (A) The ACC1 activity in HepG2 cell was detected by ELISA assay. (B) The ACC1 activity in Huh7 cell was measured. ${ }^{*} \mathrm{p}<0.05$ vs. 0 h group.

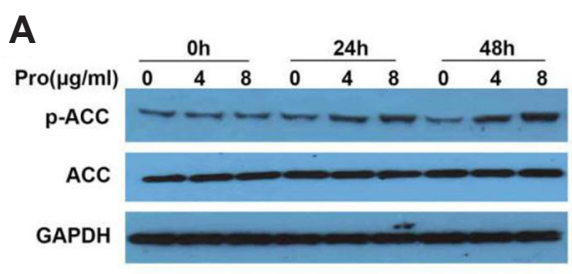

B

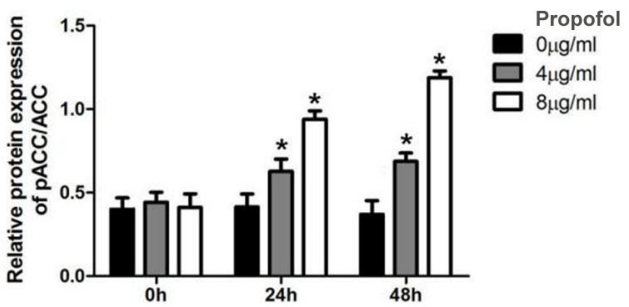

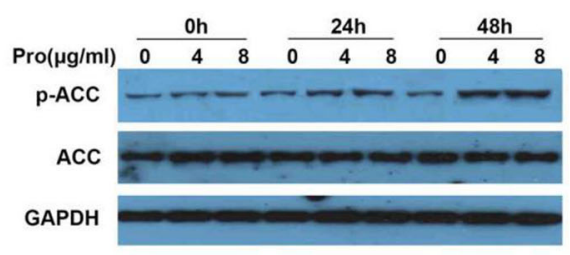

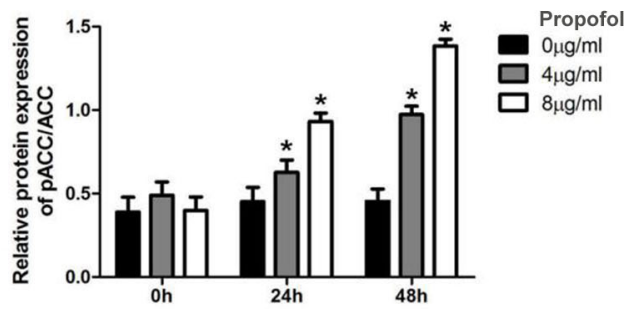

Fig. 4. Medium- and long-chain triglyceride propofol promoted the phosphorylation of acetyl coenzyme A carboxylase (ACC) in HepG2 and Huh7 cells. (A) Western blot was carried out to detect the expression and phosphorylation of ACC in different time points and concentrations in HepG2 and Huh7 cells. Pro ( $\mu \mathrm{g} / \mathrm{ml})$ indicates Propofol $(\mu \mathrm{g} / \mathrm{ml})$. (B) Relative quantitative data analyses of $\mathrm{p}-\mathrm{ACC}$ expression in HepG2 and Huh7 cells. ${ }^{*} \mathrm{p}$ $<0.05$ vs. 0 h group.

\section{MCT/LCT propofol reverses the FFA-induced phosphorylation inhibition of ACC and AMPK in HepG2 and Huh7 cells}

Finally, the phosphorylation of $\alpha$ AMPK (p-AMPK) and p-ACC (Ser79) was assessed by a western blot to assess the effect of MCT/ LCT propofol after FFA stimulation. FFA treatment remarkably inhibited the p-ACC level in both cell lines. However, the addition of the MCT/LCT propofol treatment with the FFA treatment significantly increased p-ACC and p-AMPK compared to the FFA treatment alone (Fig. 5A, B). These data provide evidence that under high-fat stimulation, the cell lines displayed a lipid metabolic pattern that was consistent with what is observed in obesity, and the MCT/LCT propofol treatment altered this signature to be less pathogenic.

\section{DISCUSSION}

Due to the effects of multiple factors, such as poor living habits and diet, the number of obese patients is on the rise. The incidence of NAFLD in China steadily increases, with the current rate reaching 15\% [14]. Because of the high incidence of NAFLD in obese patients, the issue of providing them with the appropriate anesthesia during surgery has become an area of interest. Thus, this study aimed to assess the effect of MCT/LCT propofol, which is commonly used for the induction and maintenance of general anesthesia in obese patients, on hepatic cellular metabolism, in order to provide better information on how to properly use propofol for sedation and anesthesia in obese patients, with the goal of reducing perioperative liver damage as well as perioperative mortality.

Lipid accumulation is widely accepted as the main cause of NAFLD, which induces the degradation of fatty tissue [2]. The main cause of this is a lipid metabolism disorder that is caused by fat deposition in the liver. In addition, there is reduction in cell viability because of an imbalance between the anti-oxidation/ oxidation systems, which leads to lipid peroxidation. In fact, it is actually the accumulation of TG in the liver that is the main characteristic of NAFLD [10]. In our study, we used HepG2 and Huh7 cell lines that were treated with FFAs to stimulate a high-fat condition in vitro. The induced lipid accumulation and the increased TG content in the cells after the FFA treatment demonstrated that we had successfully created a cellular model to study the effect of MCT/LCT propofol on liver cells that represented those from patients with NAFLD. In fact, the treatment with MCT/LCT pro- 
A

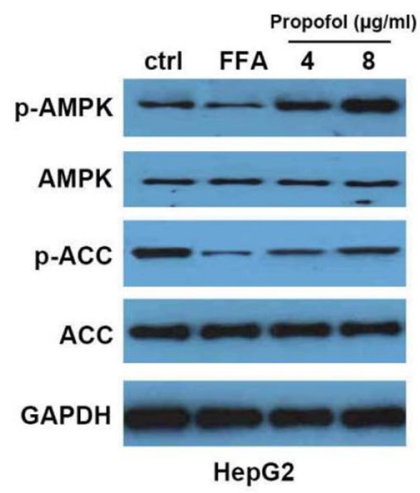

B

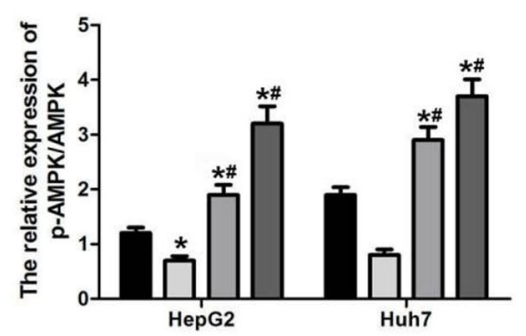

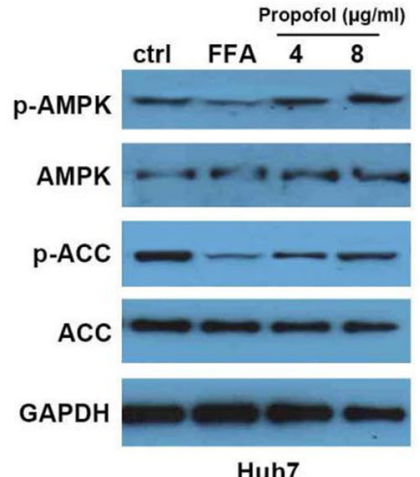

Huh7

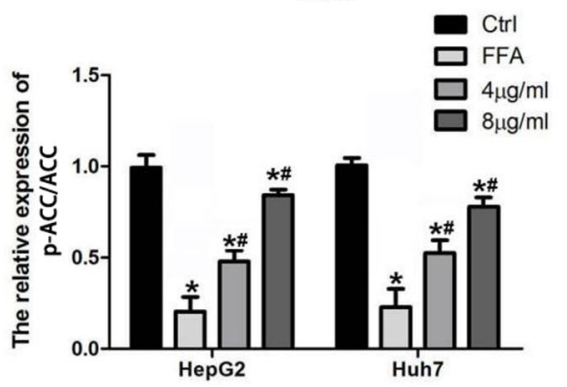

Fig. 5. Medium- and long-chain triglyceride (MCT/LCT) propofol reversed free fatty acid (FFA)-induced phosphorylation inhibition of acetyl coenzyme A carboxylase (ACC) and AMPK in HepG2 and Huh7 cells. (A) Western blot was carried out to detect the expression and phosphorylation of ACC and AMPK after $4 \mu \mathrm{g} / \mathrm{ml}$ or $8 \mu \mathrm{g} / \mathrm{ml} \mathrm{MCT/LCT} \mathrm{propofol} \mathrm{treatment} \mathrm{in} \mathrm{HepG2} \mathrm{and} \mathrm{Huh7} \mathrm{cells.} \mathrm{(B)} \mathrm{Relative} \mathrm{quantitative} \mathrm{data} \mathrm{analyses} \mathrm{of} \mathrm{p-}$ AMPK and $p$-ACC expression in HepG2 and Huh7 cells in different groups. ${ }^{*} \mathrm{p}<0.05$ vs. control group, ${ }^{\#} \mathrm{p}<0.05$ vs. FFA group.

pofol partially reversed the changes caused by the FAA treatment, suggesting that the use of this drug during surgery would not further increase fat accumulation in patients with NAFLD and it may even have some beneficial effects.

After observing the lipid and TG effects, we went on the assess lipid metabolism at the molecular level. We observed that FFA decreased the phosphorylation of both ACC and AMPK, but the MCT/LCT propofol treatment significantly promoted the phosphorylation of these proteins. When activated, AMPK induces hepatic fatty acid oxidation and ketogenesis, and it blocks cholesterol synthesis, lipogenesis, and TG synthesis [25]. Furthermore, ACC serves as a downstream effector of AMPK. When ACC is phosphorylated at Ser79 by AMPK it is inactive and downregulates lipid metabolism [26]. Our western blot data revealed that the MCT/LCT propofol increased AMPK and ACC phosphorylation levels after the reduction seen with the FFA treatment, indicating that lipid synthesis and metabolism were blocked by the drug.

It is well known that vitamin $\mathrm{E}$ has antioxidant effects, and it is used as a first-line drug for the treatment of NAFLD. The structure of propofol is similar to that of vitamin E. In vitro and in vivo studies show that propofol inhibits lipid peroxidation, protecting cells against oxidative stress and increasing the plasma antioxidant capacity [27]. In this study, propofol was assessed at 0 , 4 , and $8 \mu \mathrm{g} / \mathrm{ml}$, which were concentrations based on previous studies [28-32] and our preliminary results. In addition, FFA was used to establish the high-fat stimulation. ACC1 activity in the HepG2 and Huh7 cells was altered after an in vitro culture with $4-8 \mu \mathrm{g} / \mathrm{ml}$ propofol. These results showed that propofol $(4-8 \mu \mathrm{g} /$ $\mathrm{ml}$ ) had a significant effect on ACC. Thus, in individuals with increased ACC1 enzyme activity, such as obese patients, the application of propofol might reduce the activity of the increased ACC1 enzyme in the liver cells. In addition, in theory, the moderate inhibition of ACC1 activity with MCT/LCT propofol would not lead to an abnormal fat metabolism, softening the "second hit" in the pathogenesis of NAFLD. However, it should be noted that there is a proposal that for obese patients, a diet that contains a balance between MCTs and LCTs could help to suppress body fat accumulation [33]. Thus, in future studies, it will be important to assess the effect of the MCT/LCT component of propofol by itself to determine if that is the reason for the effects observed in this study.

After treating high-fat stimulated human hepatoma HepG2 and Huh7 cells with MCT/LCT propofol, we showed that hepatic lipid synthesis and metabolism might be affected by MCT/LCT propofol at the molecular level. Moreover, the regulation of the AMPK/ACC signal axis was involved in the molecular mechanism of the MCT/LCT propofol effect. These findings suggest that using MCT/LCT propofol was not pathogenic to the liver cells in this in vitro setting. However, more studies are required to determine if this is true in vivo and when propofol is used longterm in patients with NAFLD. 


\section{ACKNOWLEDGEMENTS}

The research was supported by Beijing Municipal Administration of Hospitals Clinical Medicine Development of Special Funding, code: ZYLX201810.

\section{CONFLICTS OF INTEREST}

The authors declare no conflicts of interest.

\section{REFERENCES}

1. Erickson SK. Nonalcoholic fatty liver disease. J Lipid Res. 2009;50 Suppl:S412-S416.

2. Day CP, James OF. Steatohepatitis: a tale of two "hits"? Gastroenterology. 1998;114:842-845.

3. Singla B, Malde AD. A prospective observational study of injection pain in children with medium plus long chain triglyceride and long chain triglyceride propofol premixed with lignocaine. Indian J Anaesth. 2018;62:214-218.

4. Yew WS, Chong SY, Tan KH, Goh MH. The effects of intravenous lidocaine on pain during injection of medium- and long-chain triglyceride propofol emulsions. Anesth Analg. 2005;100:1693-1695.

5. Theilen HJ, Adam S, Albrecht MD, Ragaller M. Propofol in a medium- and long-chain triglyceride emulsion: pharmacological characteristics and potential beneficial effects. Anesth Analg. 2002;95:923929.

6. Wu GJ, Lin YW, Tsai HC, Lee YW, Chen JT, Chen RM. Sepsisinduced liver dysfunction was ameliorated by propofol via suppressing hepatic lipid peroxidation, inflammation, and drug interactions. Life Sci. 2018;213:279-286.

7. Tsuchiya H, Ueno T, Tanaka T, Matsuura N, Mizogami M. Comparative study on determination of antioxidant and membrane activities of propofol and its related compounds. Eur J Pharm Sci. 2010;39:97-102.

8. Ge M, Yao W, Wang Y, Yuan D, Chi X, Luo G, Hei Z. Propofol alleviates liver oxidative stress via activating Nrf2 pathway. J Surg Res. 2015;196:373-381.

9. Kobayashi K, Yoshino F, Takahashi SS, Todoki K, Maehata Y, Komatsu T, Yoshida K, Lee MC. Direct assessments of the antioxidant effects of propofol medium chain triglyceride/long chain triglyceride on the brain of stroke-prone spontaneously hypertensive rats using electron spin resonance spectroscopy. Anesthesiology. 2008; 109:426-35.

10. Musso G, Gambino R, Cassader M. Recent insights into hepatic lipid metabolism in non-alcoholic fatty liver disease (NAFLD). Prog Lipid Res. 2009;48:1-26.

11. Hastings IM, Hill WG. Analysis of lines of mice selected for fat content. 2. correlated responses in the activities of enzymes involved in lipogenesis. Genet Res. 1990;55:55-61.

12. Savage DB, Choi CS, Samuel VT, Liu ZX, Zhang D, Wang A, Zhang XM, Cline GW, Yu XX, Geisler JG, Bhanot S, Monia BP, Shulman GI. Reversal of diet-induced hepatic steatosis and hepatic insulin resistance by antisense oligonucleotide inhibitors of acetyl-CoA car- boxylases 1 and 2. J Clin Invest. 2006;116:817-824.

13. Abu-Elheiga L, Matzuk MM, Kordari P, Oh W, Shaikenov T, Gu Z, Wakil SJ. Mutant mice lacking acetyl-CoA carboxylase 1 are embryonically lethal. Proc Natl Acad Sci U S A. 2005;102:12011-12016.

14. Woo M, Song YO, Kang KH, Noh JS. Anti-obesity effects of collagen peptide derived from skate (raja kenojei) skin through regulation of lipid metabolism. Mar Drugs. 2018;16:E306.

15. Yang X, Xu P, Zhang F, Zhang L, Zheng Y, Hu M, Wang L, Han TL, Peng C, Wang L, Wen L, Zeng Y, Gao R, Xia Y, Tong C, Yang Z, Qi H, Baker PN. AMPK Hyper-Activation Alters Fatty Acids Metabolism and Impairs Invasiveness of Trophoblasts in Preeclampsia. Cell Physiol Biochem. 2018;49:578-594.

16. Ma J, Kang SY, Meng X, Kang AN, Park JH, Park YK, Jung HW. Effects of rhizome extract of dioscorea batatas and its active compound, allantoin, on the regulation of myoblast differentiation and mitochondrial biogenesis in $\mathrm{c} 2 \mathrm{c} 12$ myotubes. Molecules. 2018;23:E2023.

17. Huang Y, Hao J, Tian D, Wen Y, Zhao P, Chen H, Lv Y, Yang X. Antidiabetic Activity of a Flavonoid-Rich Extract From Sophora davidii (Franch.) Skeels in KK-Ay Mice via Activation of AMP-Activated Protein Kinase. Front Pharmacol. 2018;9:760.

18. Ruderman N, Prentki M. AMP kinase and malonyl-CoA: targets for therapy of the metabolic syndrome. Nat Rev Drug Discov. 2004; 3:340-351.

19. Dihingia A, Bordoloi J, Dutta P, Kalita J, Manna P. Hexane-isopropanolic extract of Tungrymbai, a North-East Indian fermented soybean food prevents hepatic steatosis via regulating AMPK-mediated SREBP/FAS/ACC/HMGCR and PPARa/CPT1A/UCP2 pathways. Sci Rep. 2018;8:10021.

20. Jung S, Son H, Hwang CE, Cho KM, Park SW, Kim HJ. Ganoderma lucidum ameliorates non-alcoholic steatosis by upregulating energy metabolizing enzymes in the liver. J Clin Med. 2018;7:E152.

21. Li RZ, Fan XX, Duan FG, Jiang ZB, Pan HD, Luo LX, Zhou YL, Li Y, Yao YJ, Yao XJ, Leung ELH, Liu L. Proscillaridin A induces apoptosis and suppresses non-small-cell lung cancer tumor growth via calcium-induced DR4 upregulation. Cell Death Dis. 2018;9:696.

22. Hao J, Huang K, Chen C, Liang Y, Wang Y, Zhang X, Huang H. Polydatin improves glucose and lipid metabolisms in insulinresistant HepG2 cells through the AMPK pathway. Biol Pharm Bull. 2018;41:891-898.

23. Gong T, Ning X, Deng Z, Liu M, Zhou B, Chen X, Huang S, Xu Y, Chen Z, Luo R. Propofol-induced miR-219-5p inhibits growth and invasion of hepatocellular carcinoma through suppression of GPC3mediated Wnt/ $\beta$-catenin signalling activation. J Cell Biochem. 2019;120:16934-16945.

24. Zhang J, Shan WF, Jin TT, Wu GQ, Xiong XX, Jin HY, Zhu SM. Propofol exerts anti-hepatocellular carcinoma by microvesiclemediated transfer of miR-142-3p from macrophage to cancer cells. $J$ Transl Med. 2014;12:279.

25. Shirwany NA, Zou MH. AMPK: a cellular metabolic and redox sensor. A minireview. Front Biosci (Landmark Ed). 2014;19:447-474.

26. Carling D, Hardie DG. The substrate and sequence specificity of the AMP-activated protein kinase. Phosphorylation of glycogen synthase and phosphorylase kinase. Biochim Biophys Acta. 1989;1012:81-86.

27. Kahn BB, Alquier T, Carling D, Hardie DG. AMP-activated protein kinase: ancient energy gauge provides clues to modern understand- 
ing of metabolism. Cell Metab. 2005;1:15-25.

28. Bijland S, Mancini SJ, Salt IP. Role of AMP-activated protein kinase in adipose tissue metabolism and inflammation. Clin Sci (Lond). 2013;124:491-507.

29. Hardie DG. AMP-activated protein kinase: maintaining energy homeostasis at the cellular and whole-body levels. Annu Rev Nutr. 2014:34:31-55.

30. Lin SC, Hardie DG. AMPK: Sensing Glucose as well as Cellular Energy Status. Cell Metab. 2018;27:299-313.

31. Day EA, Ford RJ, Steinberg GR. AMPK as a Therapeutic Target for Treating Metabolic Diseases. Trends Endocrinol Metab. 2017; 28:545-560

32. Liu H, Liu M, Jin Z, Yaqoob S, Zheng M, Cai D, Liu J, Guo S. Ginsenoside Rg2 inhibits adipogenesis in 3T3-L1 preadipocytes and suppresses obesity in high-fat-diet-induced obese mice through the AMPK pathway. Food Funct. 2019;10:3603-3614.

33. Tsuji H, Kasai M, Takeuchi H, Nakamura M, Okazaki M, Kondo K. Dietary medium-chain triacylglycerols suppress accumulation of body fat in a double-blind, controlled trial in healthy men and women. J Nutr. 2001;131:2853-2859. 